University of Montana

ScholarWorks at University of Montana

4-1995

\title{
Visual Perception and Cognition in Infancy
}

Arlene S. Walker-Andrews

University of Montana - Missoula, arlene.walker-andrews@umontana.edu

Follow this and additional works at: https://scholarworks.umt.edu/psych_pubs

\section{Let us know how access to this document benefits you.}

\section{Recommended Citation}

Walker-Andrews, Arlene S., "Visual Perception and Cognition in Infancy" (1995). Psychology Faculty Publications. 3.

https://scholarworks.umt.edu/psych_pubs/3

This Book Review is brought to you for free and open access by the Psychology at ScholarWorks at University of Montana. It has been accepted for inclusion in Psychology Faculty Publications by an authorized administrator of ScholarWorks at University of Montana. For more information, please contact scholarworks@mso.umt.edu. 
Visual Perception and Cognition in Infancy by Carl E. Granrud Review by: ARLENE WALKER-ANDREWS

Merrill-Palmer Quarterly (1982-), Vol. 41, No. 2 (April 1995), pp. 265-267

Published by: Wayne State University Press

Stable URL: http://www.jstor.org/stable/23090538

Accessed: $16 / 12 / 2013$ 17:07

Your use of the JSTOR archive indicates your acceptance of the Terms \& Conditions of Use, available at http://www.jstor.org/page/info/about/policies/terms.jsp

JSTOR is a not-for-profit service that helps scholars, researchers, and students discover, use, and build upon a wide range of content in a trusted digital archive. We use information technology and tools to increase productivity and facilitate new forms of scholarship. For more information about JSTOR, please contact support@ jstor.org.

Wayne State University Press is collaborating with JSTOR to digitize, preserve and extend access to MerrillPalmer Quarterly (1982-). 
an introduction to the relevant literature as well as a preliminary basis for formulation of better focused research questions and preliminary theoretical and methodological approaches for addressing them. For those contributions Children's Saving is a worthy addition to the Erlbaum series of Essays in Developmental Psychology.

Department of Psychology, Livingston Campus

EDITH D. NEIMARK

Rutgers University

New Brunswick, NJ 08903

REFERENCE

SAXE, G. B. (1991). Culture and cognitive development: Studies in mathematical understanding. Hillsdale, NJ: Erlbaum.

Visual Perception and Cognition in Infancy. Carl E. Granrud (Ed.). Hillsdale, NJ: Erlbaum, 1993. Pp. viii + 355. $\$ 79.95$ hardcover; $\$ 36.00$ paper.

The chapters in this book are based on papers presented at the 23rd Carnegie Mellon Symposium on Cognition held in June 1990. There is an emphasis throughout on new methods and models for understanding the development of perception and cognition during infancy. Most of the chapters are focused on data obtained recently by the authors, with the exception of a more theoretically based chapter by Held and two commentaries. The title of the book is somewhat misleading, as seven of the chapters concern perception; only two highlight cognitive processes. Overall, the book offers a view of the exciting progress in the field of the development of perception and cognition during infancy. The authors are all researchers in the forefront of their fields of expertise. That alone makes the book worth owning. The topics reflect a new emphasis in infant perception on neurophysiological underpinnings and infants' detection of motion information and properties of objects, in contrast to an earlier stress on pattern and shape perception.

The chapters by Banks and Shannon; Teller and Lindsey; Held; and Dobson are linked by their emphasis on the limits of the infants' visual apparatus. Specifically, Banks and Shannon introduce the "ideal observer approach" for exploring perception. In brief, knowledge of maturational changes in the structure of the eye and the photoreceptors is applied 
to developmental changes in visual function. Banks and Shannon find that pre-neural characteristics account for much, although not all, of the differences between neonatal and adult contrast sensitivity and grating acuity. Likewise, the results reported by both Banks and Shannon and Teller and Lindsey indicate that poor photoreceptor efficiency can account for most, but not all, of the differences in color vision between infants and adults. Similarly, the relations between photoreceptor efficiency and either vernier acuity or grating acuity may account for differential rates of development for each type of acuity, as described by Held in his chapter. Dobson extends the ideal observer approach to older infants (15-month-olds). She concludes that distal changes in the visual system may have considerable impact on the information that reaches the visual cortex, at least for some visual functions. Held points out that the development of stereopsis and orientation selectivity cannot be easily explained at the retinal level.

The next four chapters focus on infants' perception of motion information. Aslin discusses the calibration of saccadic eye movements, speculating about why calibration extends over several postnatal months. He concludes that some oculomotor experience is necessary for accurate calibration in order to match specific neural commands to angular rotation of the eye, learn rule structures, and, most importantly, establish position constancy via optic flow information. Similarly, Kellman emphasizes the importance of spatiotemporal information for early perception, especially because kinematic information provides the most ecologically valid information. Infants are remarkably sensitive to this information, using it to extract meaningful information about objects, the spatial layout, and events. Bertenthal, focusing on biomechanical motion, asserts that from the beginning infants are sensitive to relative motion information and make use of a number of processing heuristics-perceptual vector analysis, coding theory, geometric constraints, and temporal phase relations. He concludes that knowledge-based constraints, as the name implies, are learned and that the visual experience of human gait contributes to the perception of biomechanical motion by 5 months of age.

Arterberry, Craton, and Yonas contribute the last chapter on infants' perception of motion, pointing out infants' early sensitivity to specific types of motion information. They argue that 5-month-olds can use boundary flow information and perhaps accretion and deletion of texture to perceive depth and segregate figure and ground. In contrast, they suggest that the ability to perceive object properties over time develops later. "Why?" is still an open question. Arterberry et al. submit that memory and attentional limitations may be important, but propose more forcefully that representational skills are necessary to object perception. 
The chapters by Haith and Baillargeon turn more explicitly to the investigation of cognitive processes. Haith describes the visual expectations paradigm as a way of exploring how infants form expectations for future events and act on these expectations. He finds that infants are proficient at learning where events will occur. They are especially able to use location information, remember content, and derive rules that allow them to predict sequences of events accurately. Baillargeon examines in greater depth infants' knowledge of physical relations and properties of objects, using analogues of Piaget's original tasks that do not require manual search. She concludes that 3.5-month-olds possess an object concept and recognize many properties of objects, such as height, location, and trajectory. Initially, infants' understanding of objects is limited because their representations of those objects are global, but during development those representations are elaborated and differentiated further. Baillargeon concludes that infants' approach to learning about the physical world is consistent, but varies because of changes in memory and representational abilities.

The final chapter by Siegler is, in his own words, written as a cheerleader. I echo his statement that the authors are addressing the most fundamental questions in the field with innovative methods at the earliest ages. He rightly insists, however, that the field of infancy research is falling short in two ways: (a) we need to explore more thoroughly how change occurs, and (b) we need to offer new theories that specify what is happening in perception and cognition during infancy.

In conclusion, Granrud's book includes exceptionally detailed descriptions of our knowledge of infants' perception and cognition. It provides the student of development with a rich base of information and direction for future research.

\section{ARLENE WALKER-ANDREWS}

Department of Psychology

Rutgers-The State University of New Jersey

New Brunswick, NJ 08903 